\title{
Early adiposity rebound in childhood and risk of Type 2 diabetes in adult life
}

\author{
J. G. Eriksson ${ }^{1}$, T. Forsén ${ }^{1,2}$, J. Tuomilehto ${ }^{1,2}$, C. Osmond ${ }^{3}$, D. J. P. Barker ${ }^{3}$ \\ ${ }^{1}$ Department of Epidemiology and Health Promotion, Diabetes and Genetic Epidemiology Unit, National Public Health Institute, \\ Helsinki, Finland \\ 2 Department of Public Health, University of Helsinki, Helsinki, Finland \\ ${ }^{3}$ MRC Environmental Epidemiology Unit (University of Southampton), Southampton General Hospital, Southampton, \\ United Kingdom
}

\begin{abstract}
Aims/hypothesis. Type 2 diabetes is associated with a small body size at birth and a high BMI in adult life. The aim of our study was to assess the associations between Type 2 diabetes and birth size, infant growth and age at adiposity rebound.

Methods. We carried out a longitudinal study of 8760 subjects born in Helsinki during 1934 to 1944. On average, they had 18 measurements of height and weight between birth and 12 years of age. In western countries BMI usually decreases after the age of 2 years and rises again at around 6 years - the socalled adiposity rebound. We defined age at adiposity rebound by the age of lowest BMI between one and 12 years. We identified people with Type 2 diabetes using a national register.
\end{abstract}

Results. A total of 290 individuals developed Type 2 diabetes in adult life. The cumulative incidence of Type 2 diabetes decreased progressively from $8.6 \%$ in persons whose adiposity rebound occurred before the age of 5 years to $1.8 \%$ in those in whom it occurred after 7 years $(p<0.001)$. Early adiposity rebound was preceded by low weight gain between birth and 1 year $(p<0.001)$.

Conclusion/interpretation. Large differences in the incidence of Type 2 diabetes are associated with growth rates in utero, weight gain in infancy and age at adiposity rebound. [Diabetologia (2003) 46:190-194]

Keywords Adiposity rebound, Type 2 diabetes, birthweight, infant growth, childhood obesity.
Low birth weight is associated with increased rates of Type 2 diabetes in later life [1, 2, 3, 4]. This is thought to reflect persistence of the changes in glucose and insulin metabolism which accompany slow growth in utero [5]. Because Type 2 diabetes is strongly associated with obesity in adult life, its association with the tempo of weight gain at different stages in childhood needs to be investigated. After the age of 2 years the degree of obesity of young children as measured by

Received: 29 April 2002 / Revised: 24 October 2002

Published online: 8 January 2003

(C) Springer-Verlag 2003

Corresponding author: Dr. J. G. Eriksson, Department of Epidemiology and Health Promotion, Diabetes and Genetic Epidemiology Unit, National Public Health Institute, Mannerheimintie 166, 00300 Helsinki, Finland

E-mail: johan.eriksson@ktl.fi
BMI decreases to a minimum around 6 years of age before increasing again, i.e.the so-called adiposity rebound [6]. We report associations between Type 2 diabetes and birth size, infant growth and age at adiposity rebound in a cohort of 8760 men and women, who were born in Helsinki, Finland and whose heights and weights were recorded serially from birth to the age of 12 years. People who developed Type 2 diabetes were identified through a national register of people receiving medication for the disease.

\section{Methods}

We studied a sample of 8760 men and women who were born at Helsinki University Central Hospital during 1934 and 1944, who attended child welfare clinics in the city of Helsinki and who were still resident in Finland in 1971. The majority (77\%) also went to school in Helsinki. Details of the birth, child wel- 
fare clinic and school health records have been described [7, 8, 9]. On average each person had 18 measurements of height and weight between birth and 12 years of age.

We identified 10,519 persons who had birth and child welfare records. Of those 8760 (83\%) were alive and living in Finland in 1971 when a unique personal identification number was assigned to all Finnish citizens. We were able to link these records to a national register of all persons receiving medication for Type 2 diabetes. Anti-diabetic drugs are free in Finland, subject to the approval of a physician who reviews each case history, and confirms the diagnosis of diabetes. The unique personal identifier was assigned between 1964 and 1970 to all citizens receiving reimbursement for diabetes medication. In this way we identified 290 persons in the cohort who received diabetic medication at any time between 1964 and 1998 and whose diabetes was diagnosed when they were older than 40 years. The register does not distinguish between patients with Type 1 and Type 2 diabetes. We have previously compared the national medication database with the national hospital discharge register and have shown that around 90 percent of those diagnosed after the age of 40 years and receiving medication have Type 2 diabetes [4]. We therefore use the incidence of diabetes diagnosed after 40 years as an indicator of Type 2 diabetes. The subjects whose diabetes was diagnosed before 40 years of age $(n=58)$ were excluded from the study. The Ethics Committee of the National Public Health Institute, Helsinki, approved the study.

Statistical analyses. Tests for trend were based on multivariate logistic regression by using continuous variables, which included year of birth to adjust for the effects of age. The occurrence of Type 2 diabetes was the dependent variable. For each individual, the measurements of height, weight and body mass, which in general were not ascertained in regular time intervals, were converted to Z-scores [10]. These Z-scores were calculated in such a way that each original measurement of height, weight, and BMI was transformed by using the respective mean and standard deviation derived from that one-year age stratum of the cohort which the time point of the measurements falls in. Then, for each individual we interpolated between successive Z-scores with a piecewise linear function to estimate Z-scores at all birthdays from 1 to 12 years. Following back-transformations provide estimations of the height/ weight/BMI at all these birthdays for each individual. We calculated the age at adiposity rebound, defined as the age in years between 1 and 12 years at which the lowest BMI occurred. We restricted this analysis to the 6060 subjects whose BMI was measured at each age from 1 to 12 years.

\section{Results}

A total of 290 subjects (190 men and 100 women) were receiving medication for Type 2 diabetes. The cumulative incidence was $3.3 \%$ (4.1\% among men and $2.4 \%$ among women).

Average birth weight was $3457 \mathrm{~g}$ in men and $3326 \mathrm{~g}$ in women; birth length was $50.6 \mathrm{~cm}$ and $49.9 \mathrm{~cm}$, respectively. The cumulative incidence of Type 2 diabetes was inversely related to birthweight (Table 1). It was also inversely related to ponderal index (birthweight/length ${ }^{3}, p$ for trend $=0.03$ in men and women combined). It was not related to length at birth or to the duration of gestation. It was inversely related to weight at one year $(p=0.05)$ but not to height or BMI.

The cumulative incidence of Type 2 diabetes was positively related to BMI at each age from 4 years onwards. Table 1 gives the findings at age 12 years, the oldest age for which there are data. These findings are based on 6060 children because not all children were measured within 2 years of the age of 12 . Figure 1 shows the growth of the children who later developed Type 2 diabetes. Their mean weights, heights and BMI are expressed as standard deviation differences (Z-scores) from the average values for the whole cohort, which are set at zero. A child maintaining a steady position as large or small in relation to other children would follow a horizontal path on Fig. 1. Children who later developed Type 2 diabetes, however, had small body size at birth and at 1 year, after which their weights and BMI rose progressively to exceed the average. Their heights rose more slowly and reached the average.

The average age at adiposity rebound was 5.8 years (SD 1.0), similar in boys and girls. Figure 2 shows the changes in BMI between birth and 12 years according to the age at adiposity rebound. As expected children who had an adiposity rebound at the earliest ages, up to 4 years, had the highest BMI in later childhood. They had, however, the lowest BMI up to the age of

Table 1. Cumulative incidence percentage of Type 2 diabetes according to birth weight and BMI at 12 years of age

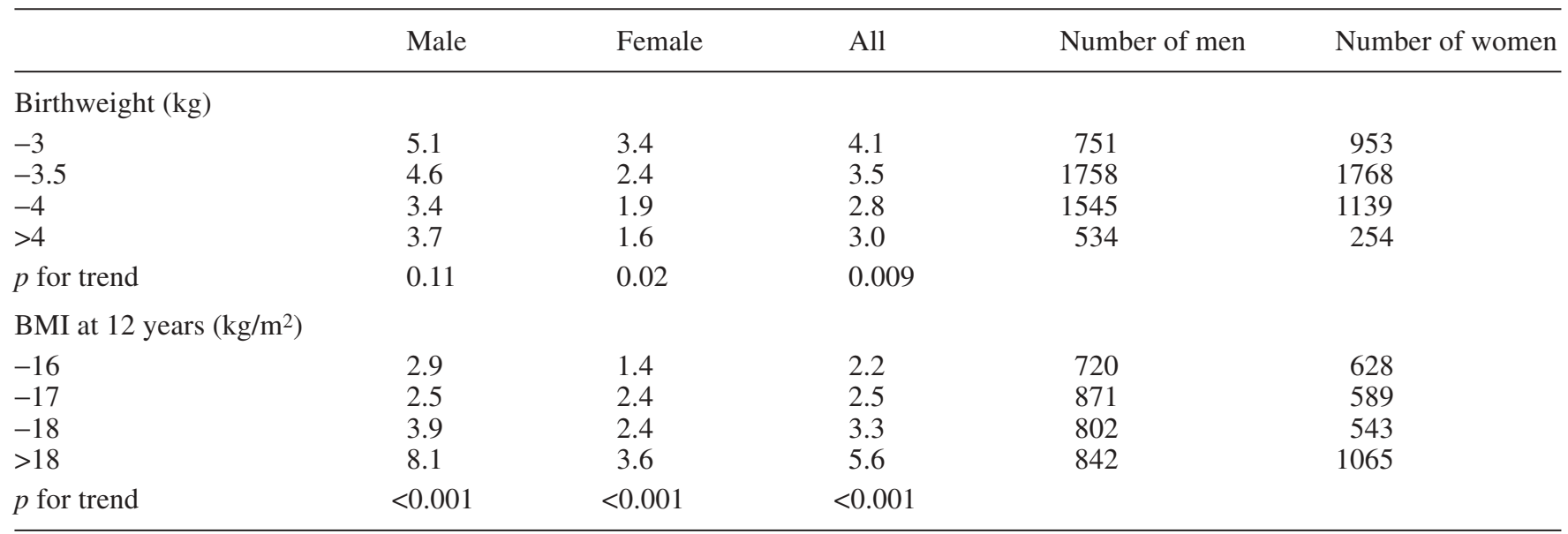




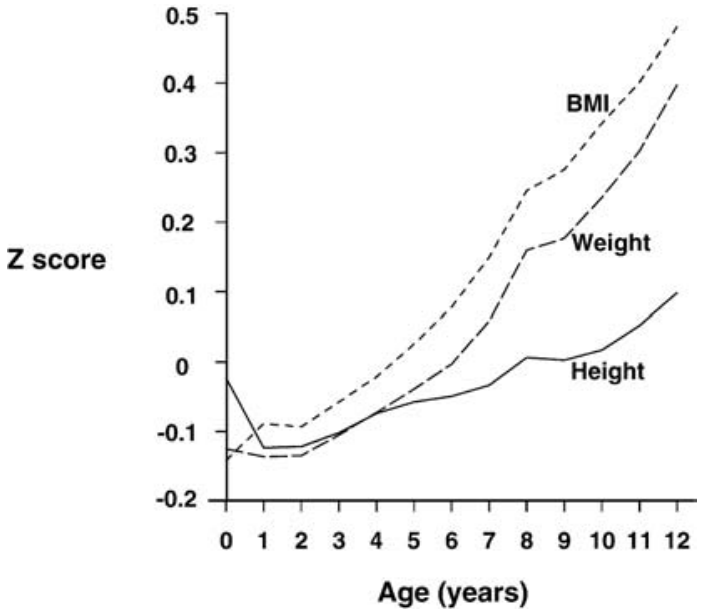

Fig. 1. Mean Z-scores for height, weight and BMI during childhood in 290 people who later developed Type 2 diabetes within a cohort of 8760 men and women. At any age, the mean Z-score for the cohort is set at 0 while the standard deviation is set at 1

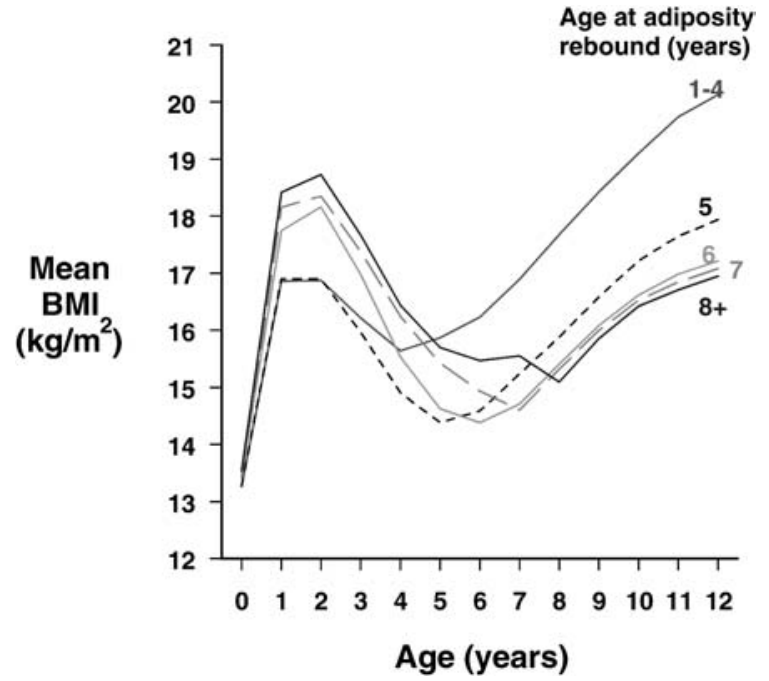

Fig. 2. Mean BMI in 6060 children according to the age of adiposity rebound

Table 2. BMI at 12 years of age and cumulative incidence of Type 2 diabetes according to age at adiposity rebound

\begin{tabular}{|c|c|c|c|c|c|c|}
\hline \multirow{2}{*}{$\begin{array}{l}\text { Age at adiposity rebound } \\
\text { (years) }\end{array}$} & \multicolumn{3}{|c|}{ Mean BMI at age $12\left(\mathrm{~kg} / \mathrm{m}^{2}\right)$} & \multicolumn{3}{|c|}{ Cumulative incidence of diabetes $\%(n)$} \\
\hline & Men & Women & All & Men & Women & All \\
\hline$\leq 4$ & 18.9 & 21.1 & 20.1 & $8.1(86)$ & $8.9(112)$ & $8.6(198)$ \\
\hline 5 & 17.7 & 18.2 & 17.9 & $6.2(904)$ & $2.5(864)$ & 4.4 (1768) \\
\hline 6 & 17.1 & 17.4 & 17.2 & $3.7(1861)$ & $2.5(1456)$ & $3.2(3317)$ \\
\hline 7 & 17.0 & 17.2 & 17.1 & $2.4(249)$ & $2.1(243)$ & $2.2(492)$ \\
\hline$\geq 8$ & 16.9 & 17.0 & 16.9 & $3.0(135)$ & $0.7(150)$ & $1.8(285)$ \\
\hline$p$ for trend & $<0.001$ & $<0.001$ & $<0.001$ & $<0.001$ & 0.002 & $<0.001$ \\
\hline
\end{tabular}

Figures in parentheses are numbers of subjects

Table 3. Age at adiposity rebound in relation to BMI and weight at 1 year of age, and change in weight from birth to 1 year

\begin{tabular}{llll}
\hline $\begin{array}{l}\text { Age at adiposity rebound } \\
\text { (years) }\end{array}$ & $\begin{array}{l}\text { BMI at one year } \\
\left(\mathrm{kg} / \mathrm{m}^{2}\right)\end{array}$ & $\begin{array}{l}\text { Weight at age one year } \\
(\mathrm{kg})\end{array}$ & $\begin{array}{l}\text { Change in Z-score for weight } \\
\text { from birth to one year }\end{array}$ \\
\hline$\leq 4$ & 16.9 & 9.7 & -0.20 \\
5 & 16.9 & 9.6 & -0.27 \\
6 & 17.7 & 10.3 & +0.06 \\
7 & 18.2 & 10.4 & +0.16 \\
$\geq 8$ & 18.4 & 10.5 & +0.25 \\
$p$ for trend & $<0.001$ & $<0.001$ & $<0.001$ \\
\hline
\end{tabular}

2 years. Table 2 shows the relation between early adiposity rebound and a high mean BMI at the age of 12 years. It also shows that, in both men and women, early adiposity rebound is associated with an increased risk of developing Type 2 diabetes in adult life. Among men and women combined the incidence of Type 2 diabetes decreased from 8.6 per cent in those in whom the adiposity rebound occurred before the age of 5 years to 1.8 per cent in those in whom it occurred after the age of 7 years.

Table 3 shows the relation between early adiposity rebound and weight and BMI during infancy (birth to
1 year). In contrast to its associations with later high BMI, early adiposity rebound is preceded by low ponderal index at birth $(p<0.001)$, low BMI at 1 year of age, low weight at 1 year and low rates of weight gain during infancy (Table 3).

\section{Discussion}

We have examined the growth of 290 children who later developed Type 2 diabetes, and compared it with other children in a cohort of 8760 people whose body 
size was measured on average 18 times (range 0-64) between birth and 12 years. Children who later developed Type 2 diabetes had low birthweight and were thin at birth, had low weight at 1 year, an early adiposity rebound and thereafter had above average weight and BMI. The age at adiposity rebound was strongly related to body size at 1 year. Children who had low weight gain between birth and 1 year and who were thin at 1 year of age rebounded at an earlier age.

$83 \%$ of the children identified through birth and clinic records were still alive and resident in Finland in 1971. Using a national register of people receiving diabetes medication we recorded a cumulative incidence of Type 2 diabetes of $3.3 \%$, with a higher incidence in men than women. Due to the register-character of our study it was restricted to subjects receiving medication for Type 2 diabetes, therefore diet-treated diabetic subjects are not included. We do not know the adult BMI of our subjects, but BMI in adolescence is known to be strongly associated with adult BMI [11]. Our study was restricted to men and women who were born in Helsinki University Central Hospital. This would introduce a bias only if the association between early growth and Type 2 diabetes differed between those born in the hospital and those born outside it. Our study was further restricted to men and women who had attended child welfare clinics, which were voluntary. The subjects could therefore be unrepresentative of all persons living in Helsinki. In particular, attendance at child welfare clinics could have been related to socio-economic circumstances. Poorer families may have made more use of the clinics because their children were less healthy, or better educated mothers may have been more willing to take advice on child-rearing. At the time of the men and women's birth, $66 \%$ of their fathers were labourers. We know that at this time in Helsinki about $60 \%$ of the men were labourers, and the social class distribution of our sample could therefore approximate to that of the city as a whole [9].

An association between Type 2 diabetes and low birthweight has been shown $[1,2,3,4,12]$. The association with low weight at 1 year is consistent with findings in Hertfordshire, UK, where low weight at 1 year was associated with the development of impaired glucose tolerance and Type 2 diabetes [1]. Previous studies have not related age at adiposity rebound to the later incidence of Type 2 diabetes. Early age at adiposity rebound has, however, been related to an increased incidence of obesity in childhood and adult life $[13,14]$. While an early adiposity rebound is associated with the development of both obesity and Type 2 diabetes, the paths of growth that lead to these two disorders differ. People who become obese tend to have a high birthweight and a high ponderal index at birth, whereas people who develop Type 2 diabetes tend to have low birthweight and to be thin at birth [15].
The processes that link low weight gain in infancy and thinness at 1 year with an early adiposity rebound are not known. The association has been described in one study [13]. Another study suggests that it reflected a post-weaning, infant diet that is low in fat but high in protein, followed by a childhood diet that is high in fat [16]. One possible explanation for the association between small body size at birth, early adiposity rebound and later Type 2 diabetes is that there are persisting alterations in body composition [4]. Babies that are small and thin at birth lack muscle, a deficiency which will persist as the critical period for muscle growth occurs in utero and there is little cell replication after birth [17]. If they develop a high body mass during childhood they can have a disproportionately high fat mass in relation to lean body mass, which will lead to insulin resistance $[12,18,19]$.

In conclusion, we have shown that Type 2 diabetes is associated with small body size at birth, followed by an early adiposity rebound. These two influences determine large differences in the risk of the disease. Children who have an early adiposity rebound tend to have had low weight gain during infancy.

Acknowledgements. We thank T. Nopanen, T. Saarinen, H. Öfverström-Anttila, A. Purtonen, T. Valle, H. Pehkonen and U. Tarvainen for abstracting the data from the records. Sigrid Rosten was responsible for data management. Liisa Toivanen co-ordinated data abstraction. This study was funded by the British Heart Foundation, Jahnsson Foundation, Finska Läkaresällskapet, Novo Foundation.

\section{References}

1. Hales CN, Barker DJP, Clark PMS et al. (1991) Fetal and infant growth and impaired glucose tolerance at age 64 . BMJ 303:1019-1022

2. Lithell HO, McKeigue PM, Berglund L, Mohsen R, Lithell UB, Leon DA (1996) Relation of size at birth to non-insulin dependent diabetes and insulin concentrations in men aged 50-60 years. BMJ 312:406-410

3. Rich-Edwards JW, Colditz GA, Stampfer MJ et al. (1999) Birthweight and the risk for type 2 diabetes mellitus in adult women. Ann Intern Med 130:278-284

4. Forsen T, Eriksson J, Tuomilehto J, Reunanen A, Osmond C, Barker D (2000) The fetal and childhood growth of persons who develop type 2 diabetes. Ann Intern Med 133:176-182

5. Fowden AL (1989) The role of insulin in prenatal growth. J Dev Physiol 12:173-182

6. Rolland-Cachera M-F, Deheeger M, Bellisle F, Sempe M, Guilloud-Bataille M, Patois E. (1984) Adiposity rebound in children: a simple indicator for predicting obesity. Am J Clin Nutr 39:129-135

7. Forsen T, Eriksson JG, Tuomilehto J, Teramo K, Osmond C, Barker DJP (1997) Mother's weight in pregnancy and coronary heart disease in a cohort of Finnish men: follow up study. BMJ 315:837-840

8. Eriksson JG, Forsen T, Tuomilehto J, Winter PD, Osmond C, Barker DJP (1999) Catch-up growth in childhood and death from coronary heart disease: longitudinal study. BMJ 318:427-431 
9. Eriksson JG, Forsen T, Tuomilehto J, Osmond C, Barker DJP (2001)Early growth and coronary heart disease in later life: longitudinal study. BMJ 322:949-953

10. Royston P (1991) Constructing time-specific reference ranges. Stat Med 10:675-690

11. Whitaker RC, Wright JA, Pepe MS, Seidel KD, Dietz WH (1997) Predicting obesity in young adulthood from childhood and parental obesity. N Engl J Med 337:869-873

12. Barker DJP, Hales CN, Fall CHD, Osmond C, Phipps K, Clark PMS (1993)Type 2 (non-insulin-dependent) diabetes mellitus, hypertension and hyperlipidaemia (syndrome $\mathrm{X}$ ): relation to reduced fetal growth. Diabetologia 36:62-67

13. Rolland-Cachera MF, Deheeger M, Guilloud-Bataille M, Avons P, Patois E, Sempe M (1987)Tracking the development of adiposity from one month of age to adulthood. Ann Hum Biol 14:219-229

14. Whitaker RC, Pepe MS, Wright JA, Seidel KD, Dietz WH (1998) Early adiposity rebound and the risk of adult obesity. Pediatrics 101:1-6
15. Eriksson J, Forsén T, Tuomilehto J, Osmond C, Barker D (2001) Size at birth, childhood growth and obesity in adult life. Int J Obesity 25:735-740

16. Rolland-Cachera M-F (1999) Obesity among adolescents: evidence for the importance of early nutrition. In: Johnston FE, Zemel B, Eveleth PB (eds) Human growth in context. Smith-Gorden, London, pp 245-258

17. Widdowson EM, Crabb DE, Milner RDG (1972) Cellular development of some human organs before birth. Arch Dis Child 47:652-655

18. Bavdekar A, Chittaranjan S, Fall CHD et al. (1999) Insulin resistance syndrome in 8-year-old Indian children. Small at birth, big at 8 years, or both? Diabetes 48:24222429

19. Eriksson JG, Forsen T, Tuomilehto J, Jaddoe VWV, Osmond C, Barker DJP (2002) Effects of size at birth and childhood growth on the insulin resistance syndrome in elderly individuals. Diabetologia 45:342-347 